\title{
EL LEGADO DE LUCIANO CAÑO, PROFESOR DE LA PRIMERA ESCUELA DE CIEGOS DE A CORUÑA (1869 ZAMORA-1936 A CORUÑA)
}

\author{
ANA L. RoDRÍGUEz DÍAZ \\ Doctora en Educación \\ ORCID iD: https://orcid.org/0000-0002-2575-0102 \\ Elisa GaVAri Starkie \\ Universidad Nacional de Educación a Distancia (UNED) \\ ORCID iD: https://orcid.org/0000-0002-7848-264X
}

Copyright: ( 2020 CSIC. La edición electrónica de esta revista se distribuye bajo los términos
de una licencia de uso y distribución Creative Commons Reconocimiento 4.0 Internacional
(CC BY 4.0).
Cómo citar/Citation: Ana L. RodRíGUEz DíAz, Elisa GAVARI STARKIE, "El legado de Luciano
Caño, profesor de la primera escuela de ciegos de A Coruña (1869 Zamora - 1936 A Coruña)",
Cuadernos de Estudios Gallegos, 67, núm. 133 (2020), págs. 229-256, https://doi.org/10.3989/
ceg.2020.133.08 


\title{
EL LEGADO DE LUCIANO CAÑO, PROFESOR DE LA PRIMERA ESCUELA \\ DE CIEGOS DE A CORUÑA (1869 ZAMORA-1936 A CORUÑA)
}

\section{RESUMEN}

Este artículo recoge el testimonio de Luciano Caño Lamas, maestro en la escuela de ciegos del Campo de la Leña de A Coruña. Las confesiones autobiográficas de esta ilustre personalidad nos desvelan las luces y las sombras de la vida y obra de un profesor ciego, que brilló en la música, como intérprete, compositor, como discursista, y en la actividad social que emprendió. Pero lo que es más relevante, sus declaraciones entrañan una visión crítica novedosa sobre el funcionamiento interno de algunos de los primeros establecimientos españoles dedicados a la enseñanza de los ciegos. Estos centros, si bien constituyen un importante legado humano y educativo, no estaban exentos de malas prácticas llegando a convivir, en ocasiones, el mercantilismo con la filantropía.

Los apuntes autobiográficos de Luciano Caño Lamas, fundamento de este artículo, han sido rescatados del Archivo de la Real Academia Gallega y contrastados con los dos únicos escritos dedicados íntegramente a la escuela de ciegos de A Coruña y su fundador, prensa histórica y otra documentación de educación especial.

PALABRAS ClAVE: Escuela de ciegos, enseñanza especial, Luciano Caño Lamas, A Coruña.

\section{O LEGADO DE LUCIANO CAÑO, PROFESOR DA PRIMEIRA ESCOLA DE CEGOS DA CORUÑA (1869 ZAMORA-1936 A CORUÑA)}

\section{RESUMO}

Este artigo recolle o testemuño de Luciano Caño Lamas, mestre na escola de cegos do Campo da Leña da Coruña. As confesións autobiográficas desta ilustre personalidade, desvélannos as luces e as sombras da vida e obra dun profesor cego, que brillou na música, como intérprete, compositor, como discursista, e na actividade social que emprendeu. Pero o que é máis relevante, as súas declaracións entrañan unha visión crítica nova sobre o funcionamento interno dalgúns dos primeiros establecementos españois dedicados ao ensino dos cegos. Estes centros, aínda que constitúen un importante legado humano e educativo, segundo as denuncias de Luciano, non estaban exentos de malas prácticas chegando a convivir, en ocasións, o mercantilismo coa filantropía.

Os apuntes autobiográficos de Luciano Caño Lamas, fundamento deste artigo, foron rescatados do Arquivo da Real Academia Galega e contrastados cos dous únicos escritos dedicados integramente á escola de cegos da Coruña e o seu fundador, prensa histórica e outra documentación de ensino especial.

Palabras Clave: Escola de cegos, Ensino Especial, Luciano Caño Lamas, A Coruña.

\section{THE LEGACY OF LUCIANO CAÑO, TEACHER AT THE FIRST SCHOOL FOR THE BLIND IN A CORUÑA (1869 ZAMORA-1936 CORUÑA)}

\begin{abstract}
This paper records the testimony of Luciano Caño Lamas, teacher in the school for the blind, Campo de la Leña, A Coruña. The autobiographical confessions of this illustrious personality reveal the lights and shadows of the life and work of a blind professor, that shone in music, as an interpreter, composer, as a discursive, and in the social activity he undertook. But what is most relevant, contain a novel critical view of the inner workings of some of the first establishments in Spain dedicated to educating the blind. Although the human and educational legacy of these schools is important, these institutions were not exempt from bad practices that led commercialism and philanthropy sometimes to sit side by side.

The autobiographical information on Luciano Caño that is the basis for this paper was retrieved from Galicia's Historical Archive. This information is considered here against the only two texts that wholly focus on A Coruña's school for the blind and its founder ${ }^{1}$, as well as against historical press articles and documents pertaining to special education.
\end{abstract}

KEY WORDS: School for the blind, specialist education, Luciano Caño Lamas, A Coruña. 
Recibido/Received: 13/06/2019

Aceptado/Accepted: 07/02/2020

\section{LAS PRIMERAS INICIATIVAS DOCENTES PARA LOS CIEGOS EN ESPAÑA}

Durante siglos, los enfermos, locos, y pobres entraban en la misma categoría formando todos ellos el colectivo de los menesterosos o mendigos. Los que padecían algún tipo de deficiencia, considerados no educables, y por lo tanto inútiles, estaban incluidos en dicho colectivo ${ }^{1}$. Un ejemplo de ello eran los invidentes: el ciego recibió sus beneficios confundido con ancianos, enfermos $y$ huérfanos $^{2}$. A finales del XVII y principios del XVIII, comienza una etapa de innovación científica que repercute en una nueva concepción de la educación. Las primeras teorías del aprendizaje humano y otras innovaciones en el campo educativo que se desarrollan en este período suponen un futuro prometedor para la enseñanza de los invidentes. Este panorama esperanzador se abre en 1748, cuando Valentín Haüy, creador de un método de lectura para los ciegos, funda la Institution National des Jeunes Aveugles y culmina en el año 1825 con la llegada del sistema Braille, ideado por Louis Braille, que se generalizó a todo el mundo ${ }^{3}$. Los progresos obtenidos en Francia en esta enseñanza tendrán repercusión en España. La Sociedad Económica Matritense presenta en 1835 un proyecto de escuela de ciegos que resulta aprobado. Se autoriza la enseñanza de ciegos en una sección del Colegio Nacional de Sordomudos y en 1841 la enseñanza de los ciegos dispone, por fin, de subvención pública. Había comenzado un año antes la introducción del Sistema Braille en España por Jaime Bruno Berenguer, profesor de la Escuela Municipal de Ciegos de Barcelona.

\footnotetext{
1 La diferencia entre enfermedad y deficiencia es reciente. De la población deficiente no han existido unas referencias explícitas, sin embargo, sí se hacía mención a tullidos, cojos, mancos, lisiados, lerdos. En una relación de los pobres existente en la ciudad gallega de Lugo, del año 1853, recogida en la obra $L a$ ciudad de Lugo en el Antiguo Régimen Siglos XVI-XIX, en el capítulo dedicado a los sectores marginales de la sociedad urbana, aparecen 22 individuos que sufren algún tipo de discapacidad: 11 son ciegos, 2 sordos, 3 impedidos y 1 cojo. Hortensio Sobrado Correa, La ciudad de Lugo en el Antiguo Régimen Siglos XVI-XIX, Lugo, Diputación Provincial de Lugo, 2001, pág. 199.

2 Rafaela Rodríguez Placer, "Instituciones y leyes protectoras para los ciegos", Revista de especialidades médicas. Obras Completas del Dr. Letamendi, 181 (5-01-1907), pág. 13.

3 Antonio Aguado Díaz, Historia de las deficiencias, Madrid, ONCE, 1995, págs. 96-103.
} 
Igualmente, en el siglo XIX en España, como sucedía en Francia, la legislación española asumirá esta competencia educativa. La Ley de Instrucción Pública, de 1857, estipulaba la creación de un establecimiento dedicado a la enseñanza de ciegos y sordos en cada uno de los distritos Universitarios como Madrid, Santiago de Compostela, Burgos, Barcelona, Valencia, Deusto y Córdoba. Estos colegios se financiaban principalmente con el apoyo de las Diputaciones provinciales. Existían, además, escuelas no oficiales que se dedicaban a la educación de los ciegos costeadas y dirigidas por personas particulares. En un principio, estos centros de enseñanza eran considerados fundaciones benéfico-asistenciales. La Ley de Beneficencia de 1849 será la primera en regular los establecimientos particulares de beneficencia, las después llamadas fundaciones $^{4}$, y su desarrollo reglamentario de 1899 distinguiría entre beneficencia general y particular.

La beneficencia particular comprendía todas las instituciones benéficas creadas y dotadas con bienes particulares, y cuyo patronazgo y administración fueron reglamentados por los respectivos fundadores, o en nombre de éstos, y confiados en igual forma a Corporaciones, autoridades o personas determinadas. Se especifica en el artículo 5 del Real Decreto que las instituciones particulares no perderán este carácter por recibir alguna subvención del Estado, de la provincia o del municipio, siempre que esta subvención no fuese necesaria o indispensable para su subsistencia. También se aclara que se respetará la voluntad de los fundadores y que son bienes propios de estos establecimientos particulares los que en la actualidad posea y los que adquiriese en lo sucesivo por limosnas, donaciones o herencias, entre otros medios ${ }^{5}$. En el año 1913, las instituciones benéfico-asistenciales pasarían a convertirse, aun manteniendo el mismo régimen legal, en fundaciones benéfico-docentes. Cabe destacar que estas fundaciones particulares sólo en muy escasa medida cubrieron las carencias formativas del colectivo de los carentes de vista, y, lo que es más importante, el establecimiento de estos colegios y escuelas para la enseñanza de invidentes no remedió la situación marginal que padecían la mayoría de los ciegos. Desde que aparece el Sistema Braille son numerosas las obras protectoras para ciegos. Pero frecuentemente se trataba de iniciativas caritativas que reafirmaban la presunta inutilidad del ciego, y a consecuencia de ello, se organizaban bajo la dirección de videntes ${ }^{6}$.

\footnotetext{
4 Juan Carlos Moreno Piñero, El tiempo de las fundaciones (Análisis del régimen jurídico de las fundaciones y propuestas para un futuro renovado), tesis de doctorado, Cáceres, Universidad de Extremadura, 2015, pág. 414.

5 Francisco López-Nieto y Mallo, La ordenación legal de las fundaciones, Madrid, La ley, 2006, págs. 324-325.

6 Javier Gutiérrez de Tovar y Beruete, La creación de la Organización Nacional de Ciegos a través de mis vivencias, Madrid, ONCE, 1988, pág. 10.
} 
Si durante muchos siglos el recurso habitual de subsistencia que la sociedad había venido ofreciendo a las personas ciegas había sido el de la caridad ${ }^{7}$, ya que resultaba un medio más económico que lo que suponía proporcionarles enseñanza; en las primeras décadas del siglo XX todavía se considera al invidente y al sordomudo como personas menores de edad, sin derechos de ciudadanía. Esta consideración de inválidos les negaba su derecho al trabajo y, por tanto, no podían emanciparse económicamente. La caridad no era la solución. Era evidente que la caridad mal entendida, reconfortante tranquilizadora de conciencias pero activa fabricante de mendigos y de picaresca, no sería el camino a seguir para salir de esa secular situación ${ }^{8}$.

Una vez que los ciegos abandonaban la enseñanza, salvo contadas excepciones, tenían que dedicarse a mendigar. Por otra parte, la mayoría de los ciegos que asistían a estas escuelas procedían de familias pobres. Esto ocasionaba que su asistencia a la escuela fuera la mínima. Un instrumento medianamente aprendido y escasos conocimientos musicales adquiridos les servían para recorrer las calles implorando caridad. Se explotaba la mendicidad como negocio. Las connotaciones negativas que acompañaban a los ciegos los hacían dignos de lástima, compasión $\mathrm{y}$, en ocasiones, objeto de explotación para familiares y otros falsos altruistas que no tenían ningún reparo a la hora de utilizar la desgracia que suponía la ceguera para obtener fama o dinero. Este fue el caso de algunos padres de niños invidentes, que se niegan a enviar a sus hijos a los colegios para aprovecharse de las limosnas que consiguen en la calle. Lo mismo ocurre con las mujeres ciegas.

Sabemos de algunos de estos padres que se niegan a enviar sus hijos a los colegios de ciegos porque, teniéndolos en la calle, ganan cuatro o cinco pesetas diarias. Lo mismo que ocurre con los niños podemos decir de las mujeres ciegas, vilmente explotadas por sus maridos o por otros hombres desalmados, unidos a ellas por vínculo irregular'.

En la tercera década del siglo XX la situación seguía siendo similar:

\footnotetext{
7 Jesús Montoro Martínez, Los ciegos en la historia, vol.5, Madrid, ONCE,1995, pág. 13.Montoro Martínez denuncia la falta de concienciación social que ha existido durante mucho tiempo por integrar a los invidentes en la sociedad: Durante muchos siglos la humanidad ha practicado la caridad con los faltos de vista pero no se ha preocupado de enseñarles a ganarse el diario sustento y les ha negado un puesto de trabajo remunerado, porque el efecto de la acción caritativa es más inmediata y no entraña responsabilidad ni problemas, en tanto que la instrucción de un invidente exige tiempo, dinero y determinadas aptitudes en maestro y discípulo...

8 Gutiérrez de Tovar y Beruete, La creación de ..., pág. 25.

9 "La mendicidad”, La lectura dominical, 1101 (6-02-1915), pág. 84.
} 
Hay en España alrededor de 5000 niños ciegos en edad escolar, de los que solo unos 200 reciben instrucción deficiente. Muchos de ellos son explotados en la mendicidad por sus familiares y todos tendrán que pedir limosna más tarde porque no recibieron ninguna educación que les preparase para luchar en la vida ${ }^{10}$.

En sus memorias, el ciego Gutiérrez de Tovar y Beruete expone la polémica de los dirigentes videntes del cupón que apareció en Madrid en 1933, que defraudaron a los ciegos y al público comprador. Tovar advierte de ello con estas palabras: Porque no hay duda que se debe estar prevenido contra determinados sedicentes altruistas, que intentan medrar a costa de ideales tan sagrados como la protección a los faltos de vista ${ }^{11}$. El profesor de ciegos don Luciano Caño Lamas en sus apuntes autobiográficos ${ }^{12}$ también denuncia las malas prácticas que contaminaban las instituciones particulares de enseñanza especial como la escuela de ciegos de A Coruña, donde desempeñó el cargo de profesor. En cuanto a esta institución de enseñanza ${ }^{13}$, Luciano manifiesta decepcionado que esta fundación respondía más que a la filantropía, a los intereses de su fundador. Así lo expresa:

No quiero relatar la historia de esta institución; los datos para escribirla obran en la Escuela y sería de desear que alguien tomase sobre si la molestia de hacer la historia de las instituciones privadas, creadas para la enseñanza de los ciegos, porque de este modo quedaría puesta en claro la cuestión de saber si dicha enseñanza pierde o gana poniéndola en manos de los particulares, que muchas veces buscan con ellas el medio de satisfacer su vanidad, cuando no el puro lucro de sus productos, por lo que la de la Coruña se refiere, solo haré algunas consideraciones para demostrar que no fue la caridad ni el amor a los faltos de vista el sostén de esta institucion ${ }^{14}$.

\footnotetext{
10 Antonio Las Heras Hervas, "La educación de los niños ciegos en las escuelas públicas", Los ciegos: revista tiflofila hispano-americana, 82 (noviembre de 1931), pág. 10.

11 Gutiérrez de Tovar y Beruete, La creación de..., pág. 16. Tovar se refiere los dirigentes videntes del cupón que apareció en Madrid en 1933, los cuales defraudaron a los ciegos y al público comprador.

12 Estos apuntes autobiográficos han sido contrastados con los dos únicos artículos existentes dedicados íntegramente a la escuela de ciegos de A Coruña y a su fundador. Estos artículos son de publicación reciente. Carlos García Cortés, "José María Salgado (1840-1919). Fundador de la escuela coruñesa de ciegos y niños pobres”, Revista Compostellanum, 61 (2016), págs. 647-695, y Ana RodríGuez DíAz, "La escuela de ciegos del Campo de la Leña. A Coruña: Los inicios de la enseñanza especial en Galicia", Cuadernos de Estudios Gallegos, vol. 61, núm. 127 (2014), págs. 251-278.

13 En 1923, la escuela de ciegos de Salgado se clasifica como establecimiento benéfico-docente, de carácter particular. Dirección General de Instrucción Pública, Gaceta de Madrid, 83 (23-03-1928).

${ }_{14}$ Esta cita pertenece a un manuscrito autobiográfico inédito de Luciano Caño Lamas del año 1919 que lleva por título Apuntes de una vida vulgar: ARChivo de LA ReAl ACADEMIA Gallega (en adelante RAG),
} 
Según se desprende de la autobiografía de dicho profesor, alumno en los primeros tiempos del Colegio Nacional de Sordomudos y Ciegos, el funcionamiento interno de estos establecimientos de enseñanza especial no era tan transparente como refleja la prensa y otra documentación que se ha conservado. Existían ciertas irregularidades administrativas, nepotismo, fraude en ciertos certámenes y eventos ${ }^{15} \mathrm{y}$ acontecimientos vividos por el propio Luciano, de los que apenas ha quedado constancia, como la inhabilitación y posterior suicidio del que fuera director del Colegio Nacional de Sordomudos, Miguel Fernández Villabrille.

\section{LUCIANO CAÑO (1869-1936): LUCES Y SOMBRAS ENTRE CASTILLA Y GALICIA}

Don Luciano Caño Lamas nació en Zamora el 13 de diciembre del año 1868 (festividad de Santa Lucía). El mismo día de su bautismo perdió la vista ${ }^{16}$. Sus padres enseguida notaron su ceguera y pensando

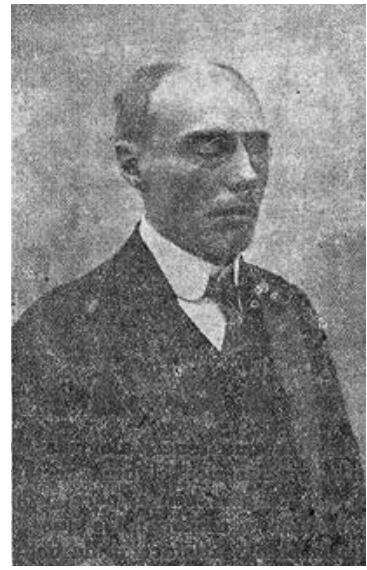

Retrato de Luciano Caño Lamas publicado por el diario zamorano Heraldo de

Zamora. "D. Luciano Caño y Lamas", Heraldo de Zamora: Diario de la tarde. Defensor de los intereses morales y materiales de la provincia, 12810 (3-10-1936), pág. 2.

que no volvería a ver, como así sucedió, comenzaron a trabajar con ahínco para que su hijo gozase de independencia tras su fallecimiento. Fue especialmente eficaz la habilidad de su madre, Marcelina Lamas, maestra de instrucción primaria, para estimular el desarrollo de la locomoción de su hijo. Adquirió, de este modo, la seguridad y confianza suficiente como para no depender de un guía y, ya en la edad adulta, recorrer con facilidad las calles de las distintas poblaciones donde residió. En cuanto a su educación intelectual, sus padres también le estimularon desde sus primeros años. Para el aprendizaje de la lectura, grabaron alrededor del

\footnotetext{
Fondos persoais: Luciano Caño, Caixa 160-4, pág. 48. Es preciso señalar que en la revista Los ciegos: revista tiflofila hispanoamericana aparece un artículo con el mismo título en que Luciano, por petición del director de la revista, resume brevemente, en tan solo dos páginas, su biografía. Luciano CaÑo LaMAS, "Apuntes de una vida vulgar", Los ciegos: revista tiflofila hispanoamericana, 45 (febrero de 1921),pág. 5. ${ }^{15}$ Un ejemplo de esta práctica que relata Luciano y que se detalla más detenidamente en este artículo, ocurre durante la celebración de un certamen pedagógico, en la sección de ciegos que estaba cargo del director del Colegio de sordomudos y ciegos de Santiago de Compostela. Si bien las intenciones del director eran loables, el evento podría considerarse fraudulento.

${ }^{16}$ RAG, Fondos persoais: Luciano Caño, Caixa 160-4 (manuscrito Luciano Caño Lamas, Apuntes de una vida vulgar, año 1919), pág. 3. Relata Luciano Caño en sus apuntes biográficos que era costumbre en Zamora exponer a los niños con poco abrigo el día de su bautismo para admiración de los curiosos que arrojaban caramelos y otras golosinas. La reacción al frío, el día de su propio bautismo, piensa Luciano que pudiera ser la causa de su ceguera.
} 
borde del plato en que comía el alfabeto en relieve y antes de servirle la comida le preguntaban las letras. Con este método, aprendió muy pronto el abecedario. Sus padres también intentaron enseñarle las sílabas valiéndose de los rótulos de las botellas, pero abandonaron la idea al ver que el resultado, esta vez, no era tan bueno ${ }^{17}$. En definitiva, el esfuerzo paternal sirvió para que Luciano pudiese leer fácilmente los libros con letra usual impresa a relieve. No obstante, esto supuso un obstáculo en su futuro aprendizaje del Braille. Luciano mostraría algunas dificultades para aprender este alfabeto cuando inicia su escolarización con el pedagogo Ramón Sant, quien había inaugurado una escuela para niños normales con la intención de educar también a los niños ciegos y sordomudos.

Así comenzó a instruirse este zamorano que, en el año 1877, cuando tan solo contaba con nueve años, ingresó en el Colegio Nacional de Sordomudos y Ciegos. El mismo Luciano reconoce que la amistad de sus padres con personalidades influyentes en la política, como Práxedes Mateo Sagasta, fueron claves para que su solicitud de ingreso en el Colegio fuera aceptada antes que otras. Sus padres le habían preparado para que su adaptación al Colegio fuese rápida lo que ayudó a que la integración a las normas del establecimiento y con los demás internos fuese buena. Las dotes imaginativas de Luciano le permitían desarrollar escenas e historietas con personajes de uno y otro sexo, con continuas transformaciones de voz, lo que entretenía a los compañeros. En las diferentes disciplinas que se impartían en el Colegio, destacó en las áreas de literatura y música. Las lecturas extraescolares despertaban más su interés que los tratados científicos. Las novelas de Julio Verne, Victor Hugo, Dumas, entre otras, le hacían forjarse una idea del mundo exterior esculpiendo su carácter y despertando su sentimiento democrático. La misma sensación le provocaba la asistencia a los conciertos y las representaciones teatrales. En la prensa también encontraría una fuente de inspiración para su ideario político. En el Colegio, la lectura de los periódicos no estaba permitida, pero un pariente que trabajaba como ebanista en el Congreso le leía los periódicos propagandistas de la Internacional que por entonces comenzaban a publicarse en España. Estas lecturas marcarían su tendencia ideológica republicana y el ideario heredado de su padre se acrecentaría con los años: Fue este el primer reflejo de una luz que, andando el tiempo llegó a ser uno de los hilos conductores de mi existencia, por el cual llegué a sacrificar mi bienestar ${ }^{18}$.

De manera menos teórica, la propia experiencia vital como interno en el Colegio contribuiría a desarrollar el amor a la justicia y la reivindicación de los

\footnotetext{
17 RAG, Fondos persoais: Luciano Caño, Caixa 160-4 (manuscrito Luciano Caño Lamas, Apuntes de una vida vulgar, año 1919), pág. 2.

18 RAG, Fondos persoais: Luciano Caño, Caixa 160-4 (manuscrito Luciano Caño Lamas, Apuntes de una vida vulgar, año 1919), pág. 14.
} 
propios derechos. Luciano confiesa la existencia de corrupción y negligencias en el establecimiento revelando que el director, por entonces, D. Miguel Fernández Villabrille, fue sometido a expediente y causa criminal. La gravedad del hecho, que Luciano desconoce, debió de ser importante ya que derivó en el suicidio del director ${ }^{19}$. La sustitución del director supuso una serie de cambios, órdenes y contraórdenes, que impedían afianzar un sustituto en dicho cargo. La falta de una autoridad consolidada también repercutía en la inquietud de los alumnos que, gracias a este desorden, se atrevieron a denunciar el comportamiento de un profesor, redactor de un conocido periódico de la época, instando una solicitud al ministro de Fomento, del que dependía el Colegio. A dicho profesor le faltaba la dedicación y conocimientos para impartir las clases y, sin duda, ocupaba este puesto en el establecimiento por influencias políticas. El resultado de la queja fue la desaparición de las aulas de dicho profesor que, según las autoridades del centro comentaron, pasaría a ocupar un puesto de mayor categoría.

Luciano abandonó el establecimiento a los veinte años, tal y como prescribía el Reglamento del Colegio. Entre los alumnos que habrían obtenido premios ordinarios en los exámenes de fin de curso figuraba su nombre: Luciano Caño y Lamas. - Enseñanza especial, medalla de primera clase. -Piano, id. de tercera ${ }^{20}$. Había hecho grandes amigos, algunos de ellos eminentes personalidades de la enseñanza especial como Eugenio Canora. Sin embargo, Luciano no hace un balance muy positivo de su enseñanza durante los 10 años de su permanencia en el internado. Su aprendizaje en el Colegio le sirvió tan solo para forjar sus hábitos de estudio. Aprendió a estudiar, y los pocos conocimientos que durante su estancia adquirió le sirvieron tan solo como base para su cultura. Poseía conocimientos científicos a un nivel básico de primaria, tocaba el piano medianamente bien y también se había iniciado en el aprendizaje del violín ${ }^{21}$.

Al margen de la educación escolar, en las vacaciones de verano recibía clases de piano en Zamora, con un profesor particular. Además, sus padres, ansiosos de proporcionar la mejor educación para su hijo, procuraron dotarle de la mayor cantidad de material posible para sus estudios. Algo muy costoso en aquella época, en que se iniciaba esta enseñanza. No obstante, todo lo aprendido le resultaba inservible para ganarse la vida y si no procediese de una familia acomodada,

\footnotetext{
19 RAG, Fondos persoais: Luciano Caño, Caixa 160-4 (manuscrito Luciano Caño Lamas, Apuntes de una vida vulgar, año 1919), pág. 26. Miguel Fernández Villabrille, condenado a 14 años de inhabilitación, se suicidó en su despacho con un vaso de láudano.

20 Discurso de don José Bambea y Sanz, profesor de música del Colegio Nacional de Sordomudos y de Ciegos, en el acto público de la solemne distribución de premios a los alumnos del mismo correspondiente al curso de 1886-1887, Madrid, Imprenta del Colegio Nacional de Sordomudos y de Ciegos, 1887 , pág. 22.

${ }^{21}$ RAG, Fondos persoais: Luciano Caño, Caixa 160-4 (manuscrito Luciano Caño Lamas, Apuntes de una vida vulgar, año 1919), pág. 32.
} 
probablemente, como les ocurría a otros ciegos, tendría que dedicarse a mendigar, tal y como el mismo testimonia:

Esta es la situación triste en la que se encuentran casi todos los ciegos españoles al abandonar los centros donde se educan; situación precursora de la mendicidad en la que yo hubiera caído a no ser por la desahogada posición social de mi familia ${ }^{22}$.

En los apuntes biográficos que dejó escritos, que son la base de esta biografía, Luciano desvela que, durante el tiempo que permaneció en Zamora, compuso varias zarzuelas. El día 7 de diciembre de 1895 estrenó con gran éxito una zarzuela en un acto titulada Zamora por dentro. También compuso distintas piezas, algunas de conciertos $^{23}$, hasta que se cansó de la composición. La creatividad de Luciano no solo se manifestaría en la composición musical, sino que también abordó la creación literaria, escribiendo dos novelas: Los hipócritas y La música en sus aspectos fisico, matemático y fisiológico. Pero lo más destacable de su pluma y lo que lo hizo famoso fue la publicación de artículos periodísticos. Cuando apareció el primer periódico diario en Zamora, La opinión, del que era director don Juan Petit, se encargó de una sección en verso denominada "Hablillas", en la que comentaba los asuntos del día más significativos. Sostuvo dicha sección cuatro años, y con estas publicaciones se hizo popular; su ingeniosa sátira era temida y elogiada por los zamoranos. Colaboró también en el semanario El mercantil zamorano, en la sección de "Bufonadas". El carácter de sus escritos, al igual que en el diario anterior, era cómico y burlesco. La sección de Luciano era lo más valorado por los lectores del semanario, que con apenas subscritores desaparecería al poco tiempo de fundarse.

Sus trabajos periodísticos, aunque le reportaban cierta fama, no estaban retribuidos. Las escasas ganancias que obtenía provenían de trabajos como afinador de pianos o tocando este instrumento en bailes u otras celebraciones de la capital zamorana o pueblos limítrofes. Su padre le presionaba para que dedicase su vida a algo práctico. Así es como, nuevamente gracias a la influencia paterna, obtuvo de la Diputación Zamorana un pequeño local para instruir a los ciegos de la provincia. No tenía asignado ningún sueldo, pues la finalidad era que obtuviese algún mérito para el futuro. Este local inaugurado el 13 de febrero de 1891 no tuvo ningún éxito. Nunca llegó a tener más de un alumno, al que Luciano, debido a las severas deficiencias que padecía, no pudo sacar ningún provecho. No era

\footnotetext{
${ }^{22}$ RAG, Fondos persoais: Luciano Caño, Caixa 160-4 (manuscrito Luciano Caño Lamas, Apuntes de una vida vulgar, año 1919), pág. 33.

${ }^{23}$ Escribiría algunas composiciones más en A Coruña: dos zarzuelas y un ensayo de ópera española titulado Gerona basado en un episodio de la Guerra de la Independencia.
} 
extraño que no prosperase este proyecto escolar, ya que existía el Colegio de Sordomudos y Ciegos de Salamanca, costeado por las diputaciones de Zamora, Cáceres, Ávila y Salamanca. Era a este colegio donde asistían los ciegos zamoranos. Luciano se lamenta de esta equivocación paterna. A su padre le hubiese sido fácil, dadas sus influencias, obtener un puesto para Luciano en el Colegio Nacional donde había estudiado, tal como había hecho Eugenio Canora, o como alternativa, el Colegio de Salamanca. Pero su destino como profesor estaría mucho más lejos de su provincia natal.

El 7 de noviembre de 1897 el Deán de Zamora, función que le correspondía por entonces al gallego Celestino Pazos, le propuso que aceptase una plaza como profesor de ciegos en la escuela de A Coruña que había sido inaugurada recientemente. Según el Deán, las ventajas que le proporcionaría dicho cargo eran muchas. Una carta recibida por el propio fundador de la escuela, que prometía, igualmente, unas excelentes condiciones profesionales, acabó por convencerle de aceptar la propuesta y viajar hasta un lugar totalmente desconocido para él. El día 22 de noviembre de 1898 fue nombrado profesor de la escuela de ciegos de A Coruña, ciudad donde Luciano llegó a integrarse y colaborar en actividades sociales diferentes como asociaciones de excursionistas, eventos benéficos e incluso llegó a participar en programas de la radio coruñesa ${ }^{24}$.

Lo cierto es que la ceguera para Luciano no suponía ningún obstáculo insalvable. La tendencia de los ciegos a huir del bullicio, de las diversiones y fiestas no era propia de su carácter. Le gustaba asistir y participar en actos públicos de cualquier tipo, sin importarle los peligros a los que pudiese exponerse. Un artículo del periódico coruñés El Orzán relata una anécdota, en la que Luciano da muestras de ese carácter intrépido y audaz, cuando acude a una de las expediciones organizadas por una agrupación de excursionistas de la que formaba parte y conocida como los Amantes del Campo:

Con la expedición fue el ilustrado ciego don Luciano Caño que
pocos habitantes de Marineda dejan de conocer pero no saben lo
intrépido que es. Nos acompañó a palpar y a notar por este medio
la oscilación del peñasco de muchas toneladas de peso, dignas de
ser visto. Para llegar a él hay obstáculos y al hacérselo saber para
decirle que podría caerse, respondió: "no importa. Otros se habrán
caído antes con visión completa ${ }^{25}$ ".

\footnotetext{
24 "Programa radiofónico. La Coruña. - E. A. J. 41. Radio-Coruña", El Pueblo gallego: rotativo de la mañana: 3306 (9-11-1934), pág. 9: Programa para hoy viernes: de dos a tres y media sesión de sobremesa, música y de noticias de prensa. De ocho a once y media de la noche, lección de francés; charla por don Luciano Caño, sobre el tema: impresiones dactilares.

25 “Los amantes del campo", El Orzán: diario independiente, 2834 (22-07-1927), pág. 2.
} 
La audacia que manifestaba en situaciones arriesgadas también le movía a presentarse ante diferentes eventos artísticos, no vinculados a su labor docente, mostrando su talento. En las fiestas del apóstol en Santiago de Compostela, el 23 de julio de 1912, participa en el Certamen de orfeones, como creador de la letra de la obra musical La aurora del combate, del famoso compositor compostelano José Gómez Veiga. En la Gaceta de Galicia, felicitan a Luciano por su sentida y hermosa poesía y lamentan su ausencia en la entrega de premios al no poder felicitarle personalmente. El periódico publica, además, una breve reseña de su biografía $^{26}$. Era frecuente que se implicase también en eventos benéficos ya fuese organizando algún festival en el Sanatorio Marítimo de Oza, al que acudían colonias de niños procedentes de diferentes provincias españoles, o en otros festivales como el de la Cruz Roja, como muestra el periódico El Noroeste del año 1897:

El próximo sábado definitivamente se celebrará en el bonito teatro del Círculo Méndez Núñez un espectáculo dirigido y organizado por el distinguido aficionado socio de la Cruz Roja don Juan Antonio de Eguílaz, destinándose sus productos al Sanatorio que tiene establecido en esta ciudad dicha caritativa Asociación. El espectáculo lo dedica el señor Eguílaz á todos los socios de la Cruz Roja y á los del Círculo Méndez Núñez. El programa es variado é interesante, pues además de algunos individuos de la Sección de Declamación que con tanto acierto dirige el señor Eguílaz, tomarán parte otros elementos de esta capital, entre ellos la banda de Zamora, dirigida por su maestro señor San José, la niña Lolita de la Iglesia, los señores don Luciano Caño, Luis González Alegre, Matías Consul, Adolfo Vega y señores Hidalgo Hervada (D. M. y D. J.) $)^{27}$.

Pese a residir en la ciudad gallega, Luciano pasaba alguna que otra temporada en Zamora. Permanecía atento a la vida cultural de su ciudad natal y, desde A Coruña, colaboró diariamente durante largo tiempo con el periódico el Heraldo de Zamora. Él obtuvo gran éxito por sus trabajos y llegó a contar en la provincia con gran número de admiradores. Su sección habitual en el periódico, "Impresiones propias”, le permitía formar parte en la lucha por el progreso de la ciudad castellana. Así se lo hacían saber los zamoranos dedicándole escritos como éste, firmado por el maestro Pascual Martin:

\footnotetext{
26 "El certamen de masas corales", Gaceta de Galicia: diario de Santiago, 165 (21-07-1912), pág.1.

27 Juan María De EGuílaz, Los monólogos en tres cuadros, Editor Florencio Fiscowich, Sucesor de Hijos de A. Gullón, Madrid, 1899, pág. 84.
} 
Agradezco en lo que valen sus impresiones y en nombre de toda la clase de maestros zamoranos envío a usted un saludo sincero dándole las gracias por su campaña en favor del progreso cientifico de esta hidalga tierra, ofreciéndome de usted humilde mentor de la niñez y amigo sincero ${ }^{28}$.

En este periódico zamorano llegó a abrirse una suscripción popular para obsequiarle con una máquina de escribir. Enseguida se alcanzó la cifra suficiente para comprarla. El día que le fue entregada la máquina, el Heraldo publicó un número extraordinario enalteciendo la figura del ilustre zamorano acompañado de una fotografía suya (de las pocas existentes). La tribuna que le brindaba el Heraldo le permitía exponer su ideología de tendencias republicanas, su fe en la educación, y su apoyo a la mujer. Muestra de ello es el libro que escribió y tituló como La moral conyugal, con un prólogo de la feminista Carmen Burgos Colombine $^{29}$ a la que apoda como mi madrina literaria. Luciano, en sus escritos, se mostraba partidario de la igualdad de los derechos de los hombres y mujeres:

A vosotras lectoras amables os dedicaré atención preferente. La mujer siempre me inspira admiración y lástima. Sea núbil, esposa o madre es la mujer siempre a mis ojos una heroica cuyo valor no quiere reconocer el hombre llegando a motejarla con el epiteto de sexo débil cuando en realidad es el más fuerte. Envanecido el hombre por poseer la fuerza material, no ve que la mujer tiene en sí la fuerza moral que es más noble e incomparablemente más grande. Doloroso es lectoras que en el siglo XX se halle la mujer, tanto en las leyes como en las costumbres en condiciones de inferioridad respecto al varón y aún es más triste que voluntariamente continúe siendo su esclava. La redención social de la mujer se impone y desde aquí contribuiré con mi granito de arena para conseguirla para lograr que deje de ser conceptuada únicamente como la hembra del varón ${ }^{30}$.

Fiel a su ideario, deseaba que sus hijas no se sintiesen despojadas de su identidad en el matrimonio ${ }^{31}$ : yo deseo que mis hijas por su medio de vida y por su

\footnotetext{
28 "Por la cultura zamorana: para don Luciano Caño", Heraldo de Zamora: Diario de la tarde. Defensor de los intereses morales y materiales de la provincia, 5588 (12-10-1914), pág. 1.

${ }^{29}$ Carmen Burgos Segui, miembro de la masonería y militante del partido republicano radical socialista, fue una de las conferenciantes más representativas en el ámbito del movimiento feminista.

${ }^{30}$ Luciano CAÑo Lamas, "Impresiones propias", Heraldo de Zamora: Diario de la tarde. Defensor de los intereses morales y materiales de la provincia, 5412 (6-03-1914), pág. 2.

${ }^{31}$ RAG, Fondos persoais: Luciano Caño, Caixa 160-4 (manuscrito Luciano Caño Lamas, Apuntes de una vida vulgar, año 1919), pág. 67.
} 
cultura no se hagan esclavas del varón con quien se unan. En el año 1929, después de más de una década, las reivindicaciones de Luciano a favor del voto de la mujer continuaban. Así se refleja en el Heraldo de Zamora:

\begin{abstract}
En algunos pueblos como en el nuestro, están disueltos [los partidos liberales] porque nunca tuvieron cohesión, porque más que otra cosa fueron personalistas (...). Otra enseñanza digna de tener en cuenta [respecto a las elecciones inglesas] es que a pesar de haber votado millón y medio de mujeres más que de varones, el curso de las cosas no varió sensiblemente (...). El voto femenino no influye en gran cosa en la marcha de la política, pero es justo mantenerlo como un indiscutible derecho de la mujer.
\end{abstract}

El voto femenino llegaría a España algo menos de dos años después, pero lo cierto es que el Heraldo ya expresó en sus páginas ideas ciertamente progresistas, que entroncaban con los pasos dados por la democracia europea ${ }^{32}$. Otro apunte relevante que muestra la personalidad de este ilustre profesor era su antipatía por actos sociales como los banquetes y homenajes que eran muy frecuentes por entonces $^{33}$. Una prueba de esto es que no dudó en rechazar su propuesta como candidato a la medalla del trabajo por su labor como docente en la escuela de ciegos de A Coruña. No se consideraba merecedor de tal medalla porque no había hecho más que cumplir con sus deberes profesionales y humanitarios.

En cuanto a su parcela más íntima y familiar, se conoce que Luciano se casó dos veces y tuvo cuatro hijos. Su primer matrimonio fue con Clotilde Soto Conde y el segundo, con la prima de ésta, Acindina Gonzalez Río, que procedía de una familia acomodada asturiana, pero pese a ello, las estrecheces económicas que tenían que soportar eran muchas. La muerte de su padre, conocido recaudador de Hacienda en Zamora, le podría haber reportado una herencia importante. Sin embargo, su padre se había vuelto a casar y había tenido varios hijos de su segundo matrimonio. La fortuna que pensaba legarle a Luciano a la muerte de su madre se redujo, por este motivo, considerablemente. De todas formas, con el transcurso de los años, su dedicación docente en la escuela de Salgado le había permitido conseguir una posición social modesta, pero con-

\footnotetext{
32 Juan José Nervión Chamorro, "El Heraldo de Zamora como fuente para la investigación en Historia Contemporánea”, Academia.edu, disponible en <https://academia.edu/35906455/> [Consulta: 08/02/2019]. Cabe señalar que algunos de los artículos de Luciano Caño no llegaron a ver la luz. El director del periódico el Heraldo temía publicarlos. Las ideas de Luciano eran demasiado avanzadas para los atavismos de la provincia zamorana y de la mayor parte de las provincias españolas.

33 Luciano Caño Lamas, "Voz de la conciencia", Heraldo de Zamora: Diario de la tarde. Defensor de los intereses morales y materiales de la provincia, 10.987 (1-07-1930), pág. 1.
} 
solidada. Por entonces, las inquietudes del profesor no eran las económicas sino otras. No se sentía satisfecho en sus tareas de maestro. Su deseo era abandonar la enseñanza o, por lo menos, apartarse de la escuela de A Coruña, y dedicarse a otros proyectos sociales más provechosos. Anhelaba que en España, como ya sucedía en algún otro país, existiese una empresa periodística que se aventurase a elaborar una edición especial en Braille dedicada a los ciegos españoles y de América Latina. Luciano se prestaría a ponerse al frente de esta edición.

\begin{abstract}
En cuanto a editoriales Braille, España carece de una imprenta oficial que pueda subvenir a las necesidades de libros pedagógicos y culturales, pese habérsele ofrecido una por la American Braille Press, entidad filantrópica americana. El gobierno de la República no concedió el oportuno presupuesto y las necesarias asistencias técnicas a que dicha Institución condicionaba la donación ${ }^{34}$.
\end{abstract}

También manifiesta su deseo de que se inventase una máquina para que los ciegos pudiesen escribir la música usual. En este sentido ya había hecho algunos intentos $^{35}$ : Quién sabe si a la falta de material de elementos es causa de que no deje a la posteridad un nombre más o menos glorioso, para que saliera de lo común del montón anónimo de lo que hasta aquí he vivido. De sus palabras se adivinaba un cierto grado de frustración. Lo mismo denota el título de su autografía: Apuntes de una vida vulgar. Pero este título con que denomina su autobiografía no hace honor a la verdad. Los detalles autobiográficos de Luciano nos develan las luces y las sombras de un ilustre pedagogo. Las mismas luces y sombras que pueblan sus vivencias más íntimas en Galicia.

En ambos matrimonios, los dos celebrados mientras residía en Galicia, Luciano confiesa que fue muy feliz, lo mismo que con el nacimiento de cada uno de sus hijos. Sobre la juventud de éstos, no llega a comentar nada en sus apuntes biográficos. Pero se conoce que su hija Clotilde Caño se casó con un industrial lucense residente en A Coruña: Cápito Carreira Vázquez, que en su juventud fue acusado de la muerte de un guardia civil junto a sus hermanas y sus padres: Manuel Carreira, un conocido sastre lucense y su mujer, Josefa Vázquez. El asesinato cometido por la familia de los Carreira, más conocido como el crimen del campo del Castillo, saltó a todas las portadas de los periódicos de la época. Los juicios

\footnotetext{
34 Gutiérrez de Tovar y Beruete, La creación de ..., pág. 13.

${ }^{35}$ RAG, Fondos persoais: Luciano Caño, Caixa 160-4 (manuscrito Luciano Caño Lamas, Apuntes de una vida vulgar, año 1919), pág. 80.
} 
se suceden desde 1919 a 1923. Cápito y sus padres llegaron a ser condenados a pena de muerte. Finalmente, solo fue acusada la madre ${ }^{36}$.

En julio de 1936, es asesinado el hijo mayor de Luciano, Gregorio Caño Soto ${ }^{37}$, militante de las juventudes izquierdistas, a manos de los sublevados en la localidad coruñesa de Oleiros. Luciano fallecería unos meses después del asesinato de su hijo, el 24 de octubre de 1936. Su muerte fue sentida tanto en su ciudad natal, como en Galicia. En el Heraldo de Zamora ${ }^{38}$, se le despide con estas palabras de admiración:

El recuerdo de don Luciano Caño Lamas quedará grabado en la mente de todos los desdichados de la Escuela de Ciegos de la Coruña, de la que era profesor y no solo entre los ciegos, sino también entre los que cultivan las Ciencias, las letras y la Música porque también supo con caracteres relevantes, brillar en los medios del Arte y del a Cultura.

La necrología aparece en el Boletín de las Escuelas Populares coruñesas ${ }^{39}$ :

El día 24 del pasado, después de recibir los Santos Sacramentos
y la bendición de su santidad falleció el señor don Luciano Caño,
profesor de la Escuela de Niños Pobres y Ciegos de esta ciudad,
que desde su fundación, en el año $1893^{40}$ por el filántropo presbí-
tero D. José María Salgado, estuvo encargado de la enseñanza
de los ciegos. Muy conocido era en la Coruña don Luciano Caño,
como músico, autor y profesor de los ciegos ya que era también
ciego; siendo admirado por su método de enseñanza, sobre el que
ha dejado notables escritos, y estaba próximo a publicar un libro

\footnotetext{
${ }^{36}$ Entre 1919 y 1923, con titulares como "La causa de los Carreira", periódicos regionales y nacionales como El Norte de Galicia, El Progreso, El Compostelano, El correo gallego, El ideal gallego, El diario de Pontevedra, La Región, El Fígaro, Crisol y otros muchos se hacen eco de la noticia.

37 Gregorio Caño Soto fue el primer coruñés al que mataron, a juzgar un artículo publicado en el periódico la Voz de Galicia del 15 de abril de 2010, titulado "Los republicanos apuntan al futuro". Lo mismo apunta Luis Lamela que dedica algún párrafo de su libro a Gregorio Caño: Luis LAmELA GARcía, Estampas de Injusticia: La Guerra Civil del 36 en A Coruña y los Documentos Originados en la Represión, A Coruña, Ediciós do Castro, 2005, pág. 107.

38 RAG, Fondos persoais: Luciano Caño, Caixa 160-4 (manuscrito Luciano Caño Lamas, Apuntes de una vida vulgar, año 1919), pág. 2.

39 Boletín de las Escuelas Populares Gratuitas, en RAG, Fondos persoais: Luciano Caño, Caixa 160-4, pág. suelta.

40 Está equivocada esta necrología en cuanto a la fecha en que se incorpora Luciano a la escuela de Salgado, ya que no fue en el año 1893 sino en el año 1898 cuando fue nombrado profesor. En años anteriores, desempeñó el cargo el maestro León Parga.
} 
sobre la enseñanza de los desgraciados que carecen del sentido de la vista.

Como recuerdo de sus obras literarias y musicales, nos deja el hermoso himno de "Los Amantes del campo", cuya letra y música escribió no hace muchos años, y que en sus excursiones cantan los amantes del campo entusiasmados.

En los muchos años que fué maestro de los ciegos en la Escuela de La Coruña, son numerosos los alumnos, que de ella han salido educados e instruidos para desempeñar cargos en el comercio y la industria, así como los que se han distinguido en la música, mereciendo aplausos en conciertos, obteniendo otros por sus labores, diplomas de méritos en varias exposiciones.

Reciba la familia del señor don Luciano Caño Lamas el más sentido pésame de la Junta Directiva, rogando a nuestros lectores una oración por el eterno descanso de su alma, por la que será aplicada por los niños de las Escuelas Populares Gratuitas la misa y comunión del primer viernes del mes actual.

\section{La doCENCIA DE LUCIANO CAÑO EN GALICIA: TRIUNFOS Y DECEPCIONES}

En el año 1893 se instaura en A Coruña en la calle Orzan n. ${ }^{\circ} 5$ una escuela dedicada a la enseñanza de los niños pobres conocida como la escuela del Campo de la Leña. Dos años después, en 1895, se destinó en este establecimiento un local para la instrucción de los ciegos. Esta escuela gratuita de ciegos y niños pobres fue fundada por el sacerdote José María Salgado Ferreiro, nacido en A Coruña en el año 1845. En esta escuela ejercería su docencia Luciano.

Es importante recuperar en este apartado algunas notas biográficas del sacerdote fundador del establecimiento para comprender las declaraciones del maestro zamorano sobre el funcionamiento de la escuela. Salgado, proveniente de una familia acomodada, realizó sus estudios eclesiásticos y ejerció el sacerdocio en Galicia, hasta que aproximadamente en el año 1870 emigra a América, junto a su madre. Estos hechos han sido constatados por todas las fuentes escritas sobre la escuela y su fundador ${ }^{41}$, pero a partir de su exilio al continente americano, el testimonio valioso de Luciano, por su convivencia diaria con Salgado durante muchos años, nos muestra algunas discrepancias sobre la vida y obra de este sacerdote con lo escrito hasta ahora.

\footnotetext{
${ }^{41}$ García Cortés, “José María Salgado...”, pág. 676; Jecoufer, “Gallegos ilustres. Don José María Salgado”, Aires Da Miña Terra. Buenos Aires. I, 27 (8-11-1908), pág. 3; RodríGuez DíAz, "La escuela de ciegos...”, pág. 259.
} 
En las causas de su partida a América comienzan tales contradicciones. Una posible causa que habría ocasionado dicha partida fueron los desórdenes políticos de la época. Pero, como afirma García Cortés, parece que su marcha de A Coruña no está tan clara y que no se han podido conseguir constancias históricas de tales hechos $^{42}$. Luciano parece tener claros los motivos. Las malas notas de Salgado le habrían impulsado a alejarse de su tierra. La información que ofrece, por su parte, García Cortés, en cuanto a la formación académica del sacerdote, es muy completa y apoya, sin pretenderlo, las declaraciones de Luciano, ya que parece ser que Salgado obtuvo pobres resultados académicos ${ }^{43}$.

A su llegada al Nuevo Continente, José María Salgado fue nombrado cura y vicario en Bragado (oeste de Buenos Aires) gracias a sus excelentes dotes de orador. En esta zona consiguió convertir al catolicismo a los indios que allí habitaban, así como a otros indígenas de tribus lejanas. Aparte de su labor evangelizadora, obtuvo varios diplomas honoríficos por parte de diferentes sociedades científicas y literarias, tanto españolas como extranjeras. Llegó a desempeñar, asimismo, el cargo de catedrático en el Liceo Universitario de Montevideo y fue uno de los más activos y entusiastas fundadores del gran Hospital Español de Buenos Aires, además de un destacado miembro de las Sociedades de Socorros Mutuos Españolas y de la Comisión "Auxilios a España ${ }^{44 "}$.

Según expone García Cortés, Salgado, una vez retornado de América en el año 1890, no venía con ningún proyecto de establecer ninguna fundación educativa. No obstante, establecerse en su domicilio coruñés, en un entorno donde abundaba la pobreza, la delincuencia y prostitución, le motivaría a buscar una medida para paliar dicha marginalidad ${ }^{45}$.

La valiosa experiencia acumulada, tras dos décadas de trabajo social con la colonia española y los emigrados gallegos, había calado hondamente en su sensibilidad ante la problemática de las personas con más carencias. Así es como, dos años después de establecerse en A Coruña, Salgado había creado una escuela dedicada a los niños pobres. La razón que motiva la fundación de esta escuela, según Luciano, es muy distinta. La razón por la que Salgado funda la escuela a su llegada a España sería la misma por la que emigró, es decir, fue la consecuencia de sus malas notas, una manera de "quitarse esa espina" de mal alumno.

En 1895 añadió en la escuela una sección para enseñar a los ciegos. García Cortés sugiere como posible hipótesis de esta ampliación educativa el hecho de

\footnotetext{
${ }^{42}$ García CoRtés, “José María Salgado...”, pág.676.

${ }^{43}$ García Cortés, "José María Salgado...”, pág.666.

44 RodríGuez Díaz, "La escuela de ciegos...”, pág. 260.

45 García Cortés, “José María Salgado...”, pág. 684. El domicilio coruñés de Salgado se encontraba próximo a los barrios de Atocha y la Torre, un espacio marginal de la ciudad.
} 
que el sacerdote habría tenido contacto con otras escuelas de educación especial, como el Colegio de sordomudos y ciegos de Santiago de Compostela. Asimismo, en sus viajes a Madrid, según confirma alguna documentación existente, parece ser que Salgado se habría asesorado en el Colegio Nacional de Sordomudos y Ciegos $^{46}$. Sin contradecir esta información, ya que existe documentación que así lo afirma, según las declaraciones de Luciano, esta sección se habría añadido a la escuela a instancia de un ciego coruñés, que se encontraba sin trabajo a la terminación de sus estudios tras salir del Colegio de la ciudad compostelana, como la mayoría de ciegos por ese entonces. Así las cosas, la escuela de niños pobres de Salgado se amplió con la enseñanza de los ciegos, mientras desempeñaba el cargo de profesor León Parga ${ }^{47}$.

Una vez se hace con la escuela de ciegos, Salgado empieza a participar con sus alumnos en varios certámenes. Así sucede con motivo de la celebración del Congreso Eucarístico en la ciudad de Lugo, en la que se organizó una exposición a la que acude Salgado con los alumnos de la escuela y su profesor León Parga. Estos son algunos de los elogios que publica la prensa recibidos en dicha Exposición Regional:

El ver como aquellos ciegos, con seis meses escasos de preparación, contestaban sin dudas ni vacilaciones, a las preguntas de Gramática, Geografía, Aritmética, Geometría, Escritura, ect., producía en nuestro ánimo, un entusiasmo tal, que momentos hubo en que no podíamos contener las lágrimas ni el movimiento de nuestros brazos para estrechar al que tanto bien hace. Imponiéndose el sacrificio de su caudal, de su bienestar y de una ${ }^{48}$.

Lo que comenta Luciano sobre dicha exposición refleja una realidad muy distinta:

En aquella ciudad, el sr. Salgado creyó conveniente para su negocio, presentar en ella a la escuela a pesar de que solo contaba algunos meses de existencia y sus alumnos no podían hacer nada digno de presentarse en público. Con todo eso, exhibió algunos loritos (alumnos ciegos) que recitaban de memoria algunas cosas haciendo como

\footnotetext{
${ }^{46}$ García Cortés, “José María Salgado...”, págs. 684-685.

47 En el artículo de la Voz de Galicia del 3 de abril de 2015, titulado "Escuela de ciegos en el Campo da Leña", figura el nombre de los profesores presentes en el acto de apertura de la escuela: León Parga y Juan Calvo Díaz.

48 "Recuerdos de la exposición. Escuela de ciegos de la Coruña", El Eco de Galicia: diario de la tarde, 3156 (12-12-1896), pág. 1.
} 
que las leían, pasando los dedos por el papel y solfeando del mismo modo, algunas lecciones. Gracias a las influencias, del entonces, gobernador de Lugo y a la protección de los gallegos que se prestan entre sí, fue premiada la escuela en dicha exposición ${ }^{49}$.

El maestro de la escuela por entonces, León Parga, se sentía desmotivado, ya que veía que la gloria y el provecho eran para el director. Por ello rompió su compromiso y creó otra institución para invidentes ${ }^{50}$. Salgado no se rindió por esta ausencia y siguió con su escuela. El refinamiento, el don de gentes, su condición de sacerdote y la circunstancia de ser natural de A Coruña hicieron que fluyese el dinero para el sostenimiento de la institución. El profesorado y la piedad que despertaban sus alumnos ciegos, eran la herramienta de la que servía Salgado para financiarse y financiar el establecimiento, siendo el único administrador, y no teniendo que rendir cuentas de sus gastos ${ }^{51}$. La estancia de José María Salgado en tierras argentinas y uruguayas durante veinte años le había proporcionado la suficiente maestría para conseguir llevar a cabo su proyecto. Esto unido a su condición de sacerdote le daba mucha ventaja sobre su contrario. Ante la ausencia del maestro Parga de la escuela, según el director debido a las excesivas exigencias del preceptor musical, era necesario contratar a otro profesor. Así es como Luciano llega a A Coruña el 22 de noviembre de 1896. Lo hace engañado, según su testimonio, por los embustes de Salgado que habrían comenzado en una carta (reclamo a la americana) que el director de la escuela le escribe augurándole, si aceptaba su propuesta de enseñar en su escuela, un excelente porvenir, mucho bienestar y poco trabajo. Solo tendría que enseñarles a los ciegos a leer, escribir y contar (palabras textuales) $)^{52}$. Nada más lejos de la realidad.

Cuando llega a A Coruña una noche invernal coruñesa en que arreciaba el viento, en vez de presentarse Salgado a recogerlo, tal como le había prometido, le espera el portero de la escuela. Tuvieron que recorrer a pie la distancia desde la estancia hasta la calle del Orzan $n .^{\circ} 5$ donde vivía Salgado. El panorama que percibió cuando conoció la escuela también fue desolador. La imagen de la escuela no se correspondía con un centro de instrucción, no había libros ni material didáctico, y solo contaba con dos niños ciegos.

\footnotetext{
${ }^{49}$ RAG, Fondos persoais: Luciano Caño, Caixa 160-4 (manuscrito Luciano Caño Lamas, Apuntes de una vida vulgar, año 1919), pág. 48.

${ }^{50}$ El Eco de Santiago, diario independiente, 283 (25-11-1896), pág. 2. El proyecto no progresó debido principalmente a la competencia que suponía la escuela de Salgado.

${ }^{51}$ RAG, Fondos persoais: Luciano Caño, Caixa 160-4 (manuscrito Luciano Caño Lamas, Apuntes de una vida vulgar, año 1919), pág. 50.

${ }^{52}$ RAG, Fondos persoais: Luciano Caño, Caixa 160-4 (manuscrito Luciano Caño Lamas, Apuntes de una vida vulgar, año 1919), pág. 49.
} 
Al entrar en la escuela, se me cayó el alma a los pies. Allí solo encontré un salón grande con tres mesas, dos de las cuales se asemejan por su forma a las empleadas en las salas de juego del monte, cuyas mesas existen en la actualidad; ocho sillas y dos niños ciegos completaban el cuadro. Nada indicaba que aquel fuese un centro de instrucción: ni un libro, ni un instrumento, ni un aparato; alli solo había promesas; promesas que jamás se vieron cumplidas ni el que las hacia tenía la intención de cumplirlas nunca ${ }^{53}$.

Salgado también mentía cuando justificaba la llegada del nuevo profesor a la escuela repitiendo una y otra vez que Luciano había sido enviado por el ministro de Fomento. Pero, lo cierto es que, gracias a las artimañas y el ingenio del director, la escuela de ciegos se nutría con el dinero que le llegaba de subvenciones, donativos oficiales, donativos de particulares y de centros gallegos en La Habana, Montevideo y Buenos Aires, y la suscripción popular. Eran comunes los actos fúnebres por las almas de los fallecidos protectores de la escuela. Había el señor Salgado hallado el medio de proseguir su America en España, descubriendo una mina cuyo filón era la caridad y compasión que los ciegos inspiran ${ }^{54}$. Sin embargo, Luciano reconoce que el trato con Salgado era cordial y que se encontraba a gusto en su compañía. La amena conversación, su refinamiento y ricas experiencias le hacían olvidar ciertos defectos suyos como la vanidad y la tacañería. Salgado le leía y comentaban la prensa diaria y algunos artículos de obras de crítica y de filosofía que hacían más agradables las largas veladas invernales. En un principio reconoce que le costó adaptarse a las costumbres refinadas y tolerantes de los coruñeses, ya que los zamoranos le parecían más familiares y francos. Salgado procuró presentarlo en todas partes para que adquiriese conocimientos que después no pudo cultivar, debido en parte a su carácter castellano muy diferente al gallego y a que su sueldo no se lo permitía. Al principio, la cantidad que cobraba era irrisoria, 60 pesetas mensuales. Más tarde, cuando la escuela tuvo una época de prosperidad, Luciano consiguió un aumento de sueldo de 100 pesetas que incluso recibía en las vacaciones.

Los alumnos avanzaban y las exigencias de la enseñanza obligaban a adquirir material. Dicho material en su mayor parte era regalado y le faltaba el orden pedagógico necesario. En estas condiciones didácticas, Luciano hizo verdaderos milagros para instruir a los niños y todos los años los exámenes públicos llamaban

\footnotetext{
53 RAG, Fondos persoais: Luciano Caño, Caixa 160-4 (manuscrito Luciano Caño Lamas, Apuntes de una vida vulgar, año 1919), pág. 50.

${ }^{54}$ RAG, Fondos persoais: Luciano Caño, Caixa 160-4 (manuscrito Luciano Caño Lamas, Apuntes de una vida vulgar, año 1919), pág. 48.
} 
la atención ${ }^{55}$. No obstante, el director de la escuela trató de acaparar la honra y el dinero del maestro zamorano para sí, al igual que había hecho con el profesor anterior. Ahora bien, a juzgar por lo escrito en la prensa, no es del todo cierto lo que dice Luciano en cuanto a que todos los honores se los llevaba el director José María Salgado. En la mayor parte de los artículos sobre la escuela de ciegos de A Coruña se cita el nombre de Luciano y si a Salgado se le atribuyen calificativos como celoso protector a Luciano el del inteligente preceptor, excelente compositor $^{56}$.

En los primeros años del siglo XX, la escuela estaba perfectamente constituida. En 1904 se hace una inspección al establecimiento en la que el subdelegado de medicina y el alcalde de A Coruña certifican que el local cumple las ordenanzas municipales relativas a salubridad e higiene además de un programa didáctico completo, por lo que se informa de la autorización para la continuidad docente ${ }^{57}$. Así las cosas, un año más tarde, al igual que diferentes instituciones de enseñanza de la provincia, la escuela del Campo de la Leña estaba preparada para ofrecer un homenaje a la obra cervantina, el Quijote de la Mancha, en su tercer centenario. En los festivales que se celebraban en la escuela figura como el espectáculo preferente la representación de una obra cómico-lírica cuyo libreto escribía el profesor José García, quedando a cargo de Luciano la composición de la partitura. Los actores eran siempre los niños pobres y los alumnos ciegos se encargaban de ejecutar la partitura. Solo en contadas ocasiones, y como excepción, un ciego formaba parte del coro. Luciano demostró que los ciegos eran capaces de ser actores también. En el programa del festival organizado en la escuela como homenaje a la obra cervantina ${ }^{58}$, entre los participantes en el festival se encontraban los alumnos ciegos de la escuela, que leyeron poesías, declamaron y cantaron algunos pasillos cómicos, mientras que en los intermedios se ejecutaron números musicales. En la revista gallega, días después de la celebración del festival, podía leerse lo que sigue:

\section{Las escuelas populares gratuitas y de ciegos y niños pobres también contribuyeron a celebrar el tercer centenario del Quijote. En esta última, o sea, la escuela de ciegos y niños pobres que tan filantró-}

\footnotetext{
${ }_{55}$ RAG, Fondos persoais: Luciano Caño, Caixa 160-4 (manuscrito Luciano Caño Lamas, Apuntes de una vida vulgar, año 1919), pág. 51.

${ }^{56}$ Estos elogios aparecen en la mayoría de las publicaciones entre otras, "Escuela gratuita de ciegos y niños pobres", Revista gallega semanario: de literatura e intereses regionales, 171 (19-06-1898), pág. 2, "Escuela de ciegos de la Coruña", Revista gallega: semanario de literatura e intereses regionales, 120 (27-06-1897), pág. 4.

57 Archivo Histórico Universitario de Santiago de Compostela, Fondo Universitario: colexios privados, Caixa, SH 228, Expediente 19, Escuela gratuita de ciegos y niños pobres, 1904.

58 Ana L. Rodríguez Díaz y Elisa GaVAri STARKI, "La presencia del Quijote en los inicios de la enseñanza especial en Galicia”, Anales Cervantinos, vol. 47 (2015), pág. 164.
} 
picamente sostiene y dirige el presbitero José María Salgado, infatigable propagador del bien y de la instrucción, dióse una fiesta por lo demás simpática ${ }^{59}$.

Dos años después de la celebración de este festival, en el año 1906, organizaron los centros culturales de Santiago de Compostela un certamen pedagógico con motivo de la celebración del patrono de la ciudad. El Sr. Letamendi, director por entonces del Colegio de Sordomudos y Ciegos de Galicia, deseoso de que se pusiesen de manifiesto las aptitudes de los alumnos, abrió en dicho certamen, cuyas bases se pueden leer en el diario El Correo de Galicia ${ }^{60}$, una sección musical dedicada a ellos en la cual había dos premios, uno para los profesores y otro para los alumnos ciegos de la región ${ }^{61}$. Tras el anuncio correspondiente del evento, con la debida antelación, no hubo ningún ciego que quisiese optar a presentarse. Una alternativa era entregar los premios a los propios alumnos del Colegio de Santiago. Pero dado lo absurdo de esta alternativa, Letamendi se pone en contacto con el Sr. Salgado y le ruega que asista al certamen algún alumno de su escuela y el profesor. A cambio de esto, Letamendi costearía su alojamiento y manutención y le otorgaría los dos premios anunciados. Se trató, pues, de un evento no del todo lícito, ya que los ganadores fueron elegidos de antemano. La precipitación con que se desencadenaron los hechos obligó a Luciano a acudir con uno de sus alumnos sin haber estudiado las obras que deberían interpretar en el concurso. Las obras eran La Polonesa de Chopin para los profesores y un vals para los alumnos. La obra de libre ejecución interpretada por Luciano fue el concierto en sol menor de Mendelssohn. Pese a haber puesto todo de su parte por embellecer las obras, la falta de tiempo para la preparación les había hecho descuidar algunos detalles, de todos modos, según lo acordado previamente, tal como se recoge en el Diario de Pontevedra, los premios fueron para Luciano y un alumno suyo:

En el concurso musical de ciegos que se celebró en Santiago por la fiestas del Apóstol coincidiendo con el certamen pedagógico han obtenido los dos primeros premios los señores don Luciano Caño y D. Jose Longueira profesor y alumno respectivamente de la Escuela gratuita de ciegos y niños pobres de la Coruña que dirige el sacerdote, D. Jose María Salgado ${ }^{62}$,

\footnotetext{
59 "Las fiestas cervantinas", Revista gallega: semanario de literatura e intereses regionales, 530 (13-051905), pág. 4.

${ }^{60}$ El Correo de Galicia: Diario independiente de avisos y noticias, s.n. (04-07-1906), pág. 2.

${ }^{61}$ RAG, Fondos persoais: Luciano Caño, Caixa 160-4 (manuscrito Luciano Caño Lamas, Apuntes de una vida vulgar, Año 1929.), pág. 77.

${ }^{62}$ El norte de Galicia: diario político y de información, 1653 (15-09-1906), pág. 2.
} 
Los premios entregados por el Sr. Vicenti en el Teatro Principal de la ciudad compostelana fueron una medalla bañada en oro y un artístico diploma. El Colegio les regaló, además, una pauta Braille, que Luciano conservaría como recuerdo de su agradable estancia en el establecimiento. El verdadero premio otorgado en aquel concurso no representaría para el maestro un triunfo musical, sino cultural: (...) saqué del aislamiento en que vivía al Colegio más importante de ciegos de Galicia $^{63}$.

El primer director del Colegio, Manuel López Navalón antecesor en el cargo de Cruz Letamendi, a pesar de haber sido alumno del Colegio Nacional, fue siempre poco partidario de la escritura usual por creerla poco práctica para los ciegos. Así que los signos alfabéticos usados en el Colegio de Santiago, la numeración y el sistema de notación musical tenían algunas diferencias con las empleadas por los ciegos en Madrid ${ }^{64}$. Luciano critica duramente al que fuera el primer director del Colegio manifestando que cometió el vanidoso disparate que muchos de los videntes dedicados a enseñar a los ciegos han cometido, es decir, el de hacer un sistema propio que solo variaba de los demás en algunos detalles, pero que no incluía ninguna ventaja positiva ${ }^{65}$. No obstante, existen numerosas declaraciones que contradicen la opinión de Luciano respecto a Navalón, a quien incluso han llegado a calificar de sabio oculto ${ }^{66}$. Navalón es considerado un ilustre pedagogo y un hombre ingenioso, cuya creatividad y habilidad le sirvió para dotar al Colegio de Sordomudos y Ciegos de Santiago de Compostela de distintos aparatos y objetos para ser utilizados para el aprendizaje de sus alumnos. Dichos aparatos han sido expuestos en diferentes exposiciones nacionales e internacionales de la época. Por otra parte, la labor de Navalón ha sido muy reconocida en Galicia y, desde el año 2009, el Colegio de Educación Regional de Sordos se ha bautizado como Centro de Educación Especial Manuel López Navalón, acogiendo a alumnos con diferentes necesidades educativas ${ }^{67}$. En palabras de Luciano, el sistema inventado por Navalón era detestable y aislaba a su colegio del resto del mundo. Así que, en el tiempo que Luciano permaneció como invitado en el Colegio de Santiago, les enseñó el Braille a los alumnos más aventajados con el

\footnotetext{
${ }^{63}$ RAG, Fondos persoais: Luciano Caño, Caixa 160-4 (manuscrito Luciano Caño Lamas, Apuntes de una vida vulgar, año 1919), pág. 79.

${ }^{64}$ Manuel López Navalón, Memoria sobre el estado del Colegio de sordomudos y de ciegos de Santiago y reformas que deben plantearse para su mejor organización, Santiago de Compostela, imprenta Manuel Miras, 1870, págs. 29-27.

${ }^{65}$ RAG, Fondos persoais: Luciano Caño, Caixa 160-4 (manuscrito Luciano Caño Lamas, Apuntes de una vida vulgar, año 1919), pág. 78.

${ }^{66}$ Así lo apodaba el dirigente republicano Emilio Castelar. "Don Manuel López Navalón. Director del Colegio de sordomudos y ciegos de Santiago", El Mortero semanario ilustrado de primera enseñanza, 171(6-12-1897).

${ }^{67}$ DOG de 4 de marzo de 2009, Orden de 6 de febrero de 2009.
} 
beneplácito del director Letamendi, desterrando así el sistema de Navalón y consiguiendo de esta forma que el Colegio de Sordomudos y Ciegos de Santiago de Compostela, según el maestro, se abriese al mundo.

Otro de los méritos otorgables al profesor de la escuela de Salgado fue su activa participación en la instauración del Centro Instructivo y Protector de Ciegos de Galicia, semejante al que existía en Madrid ${ }^{68}$. Este centro era una sociedad de socorro mutuo y de resistencia contra las campañas en contra de la mendicidad, que había sido fundada en 1894 por alumnos del Colegio Nacional de Ciegos y declarada como organización de beneficencia en 1910, y que sirvió de modelo a otras corporaciones provinciales de iguales características. En Madrid se creó por Real Decreto de 22 de enero de 1910 el primer Patronato Nacional de Ciegos, Sordomudos y Anormales. Los ciegos y sordomudos gallegos manifestaron su acuerdo con dicho Decreto lo que derivó en que dicho año se estableciese el Centro Instructivo y Protector de Sordomudos y Ciegos de Galicia. Luciano ostentaba el cargo de vicepresidente primero. En agosto de 1912 se convertiría en el presidente del Centro Instructivo de Ciegos de A Coruña. Dicho centro, una sociedad análoga a la que funcionaba en Madrid, se había constituido a raíz de la visita a la ciudad gallega del viejo líder de las asociaciones de ciegos y vocal del Patronato de Sordomudos Eugenio Canora, amigo y compañero del Colegio de Ciegos de Madrid de Luciano, que había sido invitado por José María Salgado a dar una conferencia en la escuela y a una comida en su domicilio particular ${ }^{69}$.

Ese mismo año, en 1912, aprobados los Estatutos, se determina que los niños recibiesen la enseñanza en la escuela de Salgado mientras que las niñas se educarían en un local cedido por la junta provincial de protección a la infancia. Se habían confirmado, además, los cargos que formaban la junta: presidente D. Luciano Caño Lamas; vicepresidente D. Remigio Boado de Castro; secretario, D. Marcelino Dafonte Sánchez ${ }^{70}$. Desde entonces la fundación de Salgado recibió más ayudas públicas.

Pero, como afirma Luciano, al igual que sucedía con las demás instituciones sujetas a movimientos rítmicos de ascenso y descenso en su actividad, después de una época bastante floreciente, la escuela de ciegos de A Coruña entró en un periodo de franca decadencia. Según dicho profesor, la enfermedad de Salgado, en los últimos años de la década de 1910, fue la causa de esta decadencia. El sacerdote estaba ciego y casi paralítico. El egoísmo de Salgado impidió prosperar a la escuela. Su estado le imposibilitaba dirigir con acierto la escuela y se negaba a que esas funciones recayesen sobre otra persona reservando para él el título de

\footnotetext{
68 "Centro instructivo y protector de ciegos", La Escuela Moderna, 194 (mayo de 1907), pág. 348.

69 "Lunch y banquete”, El Eco de Galicia diario católico e independiente, 1848 (25-08-1912), pág. 1.

70 "Un centro de ciegos", El Diario de Pontevedra: periódico liberal, 8491(30-08-1912), pág. 2.
} 
fundador. Al inicio de su enfermedad, José María Salgado hizo una escritura cediendo la institución a la junta de las Escuelas Populares Gratuitas, pero cuando dicha junta quiso hacerse cargo de la escuela, Salgado manifestó que esta disposición no tendría efecto hasta después de su muerte. A consecuencia de esto, la escuela estuvo diez años sin director. El material no se renovaba y apenas había alumnos en el aula. En el momento en el que fallece Salgado, en mayo del año 1919, comenzaría a cumplirse lo estipulado en la escritura. La junta de las Escuelas Populares Gratuitas formó con este fin una comisión autónoma denominada Escuela Gratuita de Ciegos y Niños Pobres fundada por José María Salgado. Si bien, en un principio, la Junta no se decidía a hacerse cargo de la escuela por la carga económica que suponía, aceptaron el legado por no querer dejarlo en manos laicas dispuestas a adquirirlo ${ }^{71}$. La escuela de ciegos seguiría funcionando en el Campo de la Leña, con el mismo profesorado, pero dependiendo del patronato de las Escuelas Populares Gratuitas. El desconocimiento de lo concerniente a la enseñanza de los ciegos, la carencia de material y la falta de alumnos (solo contaba con tres alumnos), pese a las buenas intenciones y disposición de los componentes de la comisión, retrasó el impulso que la escuela necesitaba para reorientarse y marchar por buen camino. Luciano vivía esta situación con apatía y, como él mismo reconoce, este hecho también podría considerarse como un freno al desarrollo del establecimiento. Esperemos que el tiempo haga que la escuela florezca o finalice la institución ${ }^{72}$. Se sentía cansado y desilusionado con lo que la escuela prometía. En los años de la Guerra Civil, coincidentes con la muerte de Luciano, la escuela de ciegos fundada por José María Salgado ya se había traslado a la Calle Herrerías en el lugar donde se encontraban desde hacía décadas las Escuelas Populares Gratuitas. En ese momento ya habían transcurrido más de 30 años desde la inauguración de la escuela de Salgado en el Campo de la Leña, y se había erigido como el segundo establecimiento de enseñanza de ciegos fundado en Galicia a finales del siglo XIX.

\section{CONCLUSIÓN}

A partir de la Ley Moyano de 1857, se inicia la instauración de los colegios y escuelas para sordomudos y ciegos en las provincias españolas. En la escasa información existente sobre la implantación de estos colegios, abundan las críticas referentes a las pobres condiciones educativas que presentaban, la escasez de material, la carencia de financiación, la falta de uniformidad didáctica y de metodología debido a la inexistente conexión entre los pocos centros establecidos.

\footnotetext{
71 García Cortés, “José María Salgado...”, pág.691.

${ }^{72}$ RAG, Fondos persoais: Luciano Caño, Caixa 160-4 (manuscrito Luciano Caño Lamas, Apuntes de una vida vulgar, año 1919), pág. 77.
} 
Las denuncias de Luciano Caño Lamas que han quedado expuestas en este artículo van en una dirección diferente y nos muestran irregularidades y deficiencias en el funcionamiento interno de alguna de estas instituciones docentes de enseñanza especial y de su entorno donde los intereses de políticos, fundadores o directores primaban por encima de la filantropía.

A finales del siglo XIX, la presunta inutilidad de las personas ciegas, estigma que perdurará durante mucho tiempo, despertaba la compasión popular. De ahí que las obras protectoras hacia este colectivo se orientaran hacia la caridad. Los fundadores y directores de estas escuelas acostumbraban a ser videntes que sostenían sus establecimientos con limosnas, regalos o subvenciones. En ocasiones, tal y como testimonia Luciano, estas fundaciones respondían al lucro propio de fundadores deseosos de obtener dinero y fama. El mencionado profesor pone en tela de juicio los certámenes celebrados con el fin de comprobar el progreso de los alumnos ciegos. Estas exhibiciones no eran tan transparentes como daba a entender la prensa. Tampoco la organización de estas escuelas. La ambición de los fundadores se anteponía al progreso de estos centros de enseñanza.

Es importante que el testimonio de Luciano sea conocido. Pero también lo es recordar que es un testimonio escrito en una época concreta, con la subjetividad propia de una autobiografía, con logros, decepciones y frustraciones personales y también sociales, como corresponde a una personalidad comprometida con una determinada ideología y una causa a la que dedicó la mayor parte de su vida: la enseñanza de los discapacitados visuales. Dicho profesor, ciego de nacimiento, se reconoce en una posición privilegiada con respecto a los invidentes de su generación. Desde su infancia contó con el apoyo incondicional de una familia acomodada que le procuró los estímulos intelectuales y sociales necesarios para conseguir su independencia económica. Algo que resultaba inviable para la mayoría de los ciegos.

Por otra parte, sin restar peso a las acusaciones del mencionado profesor, también se hace patente en el artículo que, en estos primeros establecimientos de enseñanza especial, de finales del siglo XIX y principios del XX, como el fundado por el sacerdote José María Salgado, la intención educativa ya había germinado, se contaba con docentes comprometidos con su tarea y los ciegos comenzaban, por fin, a instruirse. Un hito relevante para la sociedad y la historia de la educación. En este sentido, el legado de Luciano a la enseñanza especial fue, sin duda, significativo. En Galicia, su docencia, su participación en conferencias y diferentes eventos y su compromiso con la fundación de un Patronato creado exprofeso para sordomudos, ciegos y otros discapacitados gallegos contribuyeron a mejorar la situación social y educativa de los que, como él mismo, carecían de uno de los sentidos más preciados, la vista. En la actualidad, contrariamente a lo que se deduce del testimonio de dicho profesor, su cometido fue reconocido, tanto es así, que en la ciudad coruñesa una calle lleva su nombre: Rúa Luciano Caño. 


\section{BIBLIOGRAFÍA}

Aguado Díaz, Antonio, Historia de las deficiencias, Madrid, ONCE, 1995.

Burgos Bordonau, Esther, Historia de la enseñanza musical para ciegos en España, 1830-1938, Madrid, ONCE, 2004.

Burgos Bordonau, Esther, "Repertorio de la Legislación social y educativa entre 1822 y 1938 y su incidencia en la enseñanza de las personas ciegas", Cuadernos de Historia del Derecho, 13 (2006), págs. 261-279.

Colegio Nacional de sordomudos y ciegos, Discurso de don José Bambea y Sanz, profesor de música del colegio nacional de sordomudos y de ciegos en el acto público de la solemne distribución de premios a los alumnos del mismo correspondiente al curso de 1886-1887, Madrid, Imprenta del Colegio Nacional de Sordomudos y de Ciegos, 1887.

Eguílaz, Juan María de, Los monólogos en tres cuadros, Madrid, Editor Florencio Fiscowich, Sucesor de Hijos de A. Gullón, 1899.

García Cortés, Carlos, "José María Salgado (1840-1919). Fundador de la escuela coruñesa de ciegos y niños pobres”, Revista Compostellanum, 61 (2016), págs. 647-695.

Gutiérrez de Tovar y Beruete, Javier, La creación de la Organización Nacional de Ciegos a través de mis vivencias, Madrid, ONCE, 1988.

Lamela García, Luis, Estampas de Injusticia: La Guerra Civil Del 36 en A Coruña y los Documentos Originados en la Represión, A Coruña, Ediciós do Castro, 2005.

Las Heras Hervas, Antonio, "La educación de los niños ciegos en las escuelas públicas", Los ciegos: revista tiflofila hispano-americana, 82 (noviembre de 1931), págs. 7-10.

López Navalón, Manuel, Memoria sobre el estado del Colegio de sordomudos y de ciegos de Santiago y reformas que deben plantearse para su mejor organización, Santiago de Compostela, imprenta Manuel Miras, 1870.

López-Nieto y Mallo, Francisco, La ordenación legal de las fundaciones, Madrid, La ley, 2006.

Moreno Piñero, Juan Carlos, El tiempo de las fundaciones. (Análisis del régimen jurídico de las fundaciones y propuestas para un futuro renovado), tesis de doctorado, Cáceres, Extremadura, Universidad de Extremadura, 2015.

Montoro Martínez, Jesús, Los ciegos en la historia, 5 vols., Madrid, ONCE, 1995.

Rodríguez Díaz, Ana, "La escuela de ciegos del Campo de la Leña. A Coruña: Los inicios de la enseñanza especial en Galicia", Cuadernos de estudios gallegos, vol. 61, núm. 127 (2014), págs. 251-278.

Rodríguez Díaz, Ana y Gavari Starkie, Elisa, "La presencia del Quijote en los inicios de la enseñanza especial en Galicia”, Anales Cervantinos, vol. 47 (2016), págs. 159-170.

Rodríguez Placer, Rafaela, "Instituciones y leyes protectoras para los ciegos", Revista de especialidades médicas. Obras Completas del Dr. Letamendi, año X, (5-01-1907), págs. 13-20.

Sobrado Correa, Hortensio, La ciudad de Lugo en el Antiguo Régimen. Siglos XVI-XIX, Lugo, Diputación Provincial de Lugo, 2001. 